\title{
Tradición Literaria y Heroínas Indias en La Araucana
}

La crítica tradicional de La araucana ha insistido en señalar el carácter verista de la obra de Ercilla. Para ello era suficiente aceptar como totalmente válidas las repetidas afirmaciones del autor acerca de que escribía una obra fiel a la verdad histórica; no es extraño, así, que La araucana fuera considerada como una especie de "crónica rimada" de las guerras del Arauco. En esta interpretación literal del sentido del poema los episodios intercalados resultaban difíciles de justificar ya que quitaban unidad a la epopeya central; sin embargo, una visión interesada en el poema como obra artística tiende a sustituir la interpretación tradicional de La araucana. Hoy ya parece ocioso afirmar que la veracidad de algunos datos históricos no implica que La araucana sea una crónica de la conquista. El poema de Ercilla fue concebido como obra "literaria" escrita de acuerdo con ciertos cánones retóricos y así fue considerada en su época. ${ }^{1}$

1 J. T. Medina, sin rechazar el valor literario de La araucana, insiste en documentar la verdad histótica y en cierto modo exagera el carácter verista del poema (J. T. Medina, La Araucana de Don Alonso de Ercilla y Zúñiga. Edición del Centenario (Santiago de Chile, 1918) Ilustraciones, II). Se ubica así en una larga tradición de crítica que coincide en afirmar el carácter esencialmente histó. rico de La araucana. Más recientemente Menéndez Pidal reitera en varios trabajos la idea de que el realismo de la epopeya medieval reaparece en la épica re. nacentista española. Para Menéndez Pidal, La araucana es "poesía historial" y Ercilla, oponiéndose a las teorías estéticas de Ariosto, intenta escribir una "historia verdadera" de las guerras del Arauco (cf. Los españoles en la bistoria y en la literatura (Buenos Aires, 1951) p. 205; v. además su artículo "Poesía e historia en el Mio Cid", NRFH, III (1949) p. 126). A pesar de las objeciones de J. B. Avalle-Arce a! libro de F. Pierce, La poesía épica del siglo de Oro, $2^{\mathrm{a}}$ ed. (Madrid. 1968), en su reseña en MLN, LXXVIII, no 2 (1963) 205-210, no nos parece desacertada la idea de considerar la poesia épica renacentista como esencialmente "literaria". En un artículo polémico anterior "History and poetry in the heroic poem of the Golden Age", HR, XX (1952) 302-312, Pierce se opone a la analogía que establece Menéndez Pidal entre la épica medieval y la renacentista y afirma el carácter retórico y artístico del poema épico español en el Siglo de Oro. Según Pierce los contemporáneos de Ercilla no consideraban 
Ercilla, desde el comienzo, intentó componer un poema épico. Pero un poema épico que no se ajustaba a las fórmulas de los grandes mo. delos clásicos, desde la Ilíada a la Etteidla o aun a la Farsalia, ${ }^{2}$ sino que trataba de dar dimensión heroica a un relato de sucesos verídicos según formas poéticas nuevas en el género. Esta voluntad de verdad, presente hasta en la recreación de la historia de Dido, por ejemplo, configura las características del poema. ${ }^{3} \mathrm{La}$ ausencia de un héroe central o la insistencia en menudos detalles documentales responden seguramente a esta preocupación por la objetividad histórica; peto Ercilla no es un mero cronista y junto a la historia está su concepción del poema como unidad artística. En repetidas oportunidades Ercilla menciona las limitaciones que la verdad histórica impone a su tema y expresa el deseo de conferir mayor variedad a la obra (cf. por ejemplo XV,4). Los cinco episodios de heroinas indias intercalados a lo largo de las tres partes del poema cumplen esta función. Están pensados como adorno retórico y como contraparte de los pasajes bélicos. No representan una ruptura en el hilo del relato ni quitan unidad a la obra sino que contribuyen a crear un ritmo de alternancia temática. Pero estas heroínas no parecen ser recuerdo de araucanas que Ercilla pudo haber conocido. ${ }^{4}$ Ercilla deja a un lado aquí la intención documental y crea figuras literarias que se inspiran en personajes y episodios del Orlando furioso de Ariosto. Gua. colda, Tegualda y Glaura son seres ficticios que actúan bajo nombres aparentemente indios, en un ambiente idealizado que nada tiene en

La araucana una obra histórica sino esencialmente artística. Claude Dumas, en un artículo "Reflexions sur quelques points d'histoire dans La araucana", Bulletin de la Faculté des Lettres de Strasbourg, XLIII (1965) 735-749, comparte esta idea después de haber estudiado las crónicas contemporáneas de La araucana que tratan de la sublevación de 1553 a 1558 en el Arauco. En la misma actitud, C. Albarracín Sarmiento analiza el uso del pronombre de primera persona para caracterizar los tipos de narrador en La avaucana, que no siempre deben ser identificados con la persona Ercilla como cronista presencial de los hechos que narra ("Pronombres de $1^{\text {a }}$ persona y tipos de narrador en La araucana", BRAE, XLVI (1966) p. 314 y ss.).

2 M. Chevalier, L'Arioste en Espagne (Bordeaux, 1966) p. 144 a 146 explica convincentemente las diferencias que separan a Lucano de Ercilla. Aparte de las conocidas imitaciones directas (descripción de la caverna de Fitón, XXIII, 46 y ss. que corresponden a la descripción de la cueva de Erictho, Farsalia, VI, 642 y ss.) y de su intento de seguir a Lucano en la caracterización de la naturaleza y la geografía locales, La araucana poco tiene en común con el poema que narra la lucha épica de César y Pompeyo.

3 M. R. Lida. "Dida y su defensa en la literatura española", RFH, IV (1942) 209.257 y 313-382.

4 J. T. Medina, "Las mujeres de La araucana", Hispania, XI (1928) 1-12, acepta sólo parcialmente el carácter literario de estas heroinas y cree que Ercilla describe figuras $\mathrm{y}$ hechos que vio en Chile. Según Medina, Ercilla fue testigo o tomó parte en algunos de estos episodios (cf. el relato de Tegualda y el de Glaura). Esta interpretación del recurso literario de presentarse como personaje en la acción parece hoy insostenible. 
común con la naturaleza de Chile. Los personajes se expresan en una lengua elaborada y retórica y se ven envueltos en aventuras de tono literario que no responden a la realidad histórica.

Ercilla se refiere también a las mujeres indias en varios pasajes del poema. Pero aun en estas menciones es difícil determinar el grado de verosimilitud de sus comentarios. En el canto IV, 30 hace una escueta referencia a las viudas de guerreros:
Otro, pues, que de Córdoba se llama mozo de grande esfuerzo y valentía tanta sangre araucana allí derrama, que hizo más de cien viudas aquel día: por una que venganza al cielo clama, saltan todas las otras de alegría; que al fin son las mujeres variables, amigas de mudanzas y mudables.

La posible alusión a un rasgo bárbaro de las mujeres araucanas, el regocijo ante la muerte de sus maridos, está atenuada por la reflexión general de los dos últimos versos de la estrofa. Ercilla traduce aqui, con algunas variantes, un conocido verso de la Eneida sobre la inconstancia de las mujeres: cf. IV, 569-70: "varium et mutabile semper/ femina." Se trata pues de un topos literario, más que de una referencia 2 un hecho real.

La segunda mención se da en el canto X, 3-9; es más extensa y la única que recuerda probablemente una costumbre indígena. Según Er. cilla, desde la derrota sufrida por los españoles en el intento de repoblar la ciudad de Concepción, las mujeres acompañaron a sus maridos a la guerra luchando contra el enemigo cuando era necesario. En el prólogo en prosa encontramos una aserción semejante: "es tanta la falta de gente por la mucha que ha muerto en esta demanda, que para hacer más cuerpo y henchir los escuadrones vienen también las mujeres a la guerra y peleando algunas veces como varones, se entregan con grande ánimo a la muerte." En el canto $\mathrm{X}$ se reitera el dato histórico: 6, v. 7.8:

De aquí tuvo principio en esta tierra venir también mujeres a la guerra.

\footnotetext{
p. 12.

- Véase Prólogo del Autor, La araucana (México: Editorial Porrúa, 1968)
} 
En las estrofas 3 a 8 presenta Ercilla a las indias que participan en la lucha y persecución de los españoles. Encarece aquí la valentía y crueldad de las mujeres en una descripción que acentúa rasgos hombrunos y aun grotescos en las araucanas (cf. especialmente estrofa 5, v. 4-8).

Una tercera referencia se encuentra en el canto XXIX, 21. Tucapel y Rengo se aprestan a combatir y los araucanos entusiasmados con la justa apuestan diversas posesiones: cf. v. 4.8:

quien apostaba ropa, quien ganado quien tierras de labor, quien granjerías; algunos que ganar no deseaban, las usadas mujeres apostaban.

El comentario no parece tener como propósito señalar una costumbre indígena y es tan general que no se puede deducir un contenido docu. mental sobre las mujeres araucanas.

Estos ocasionales y escuetos textos en que se habla de las indias nos presentan seres indiferenciados (en uno de los casos rudos y poco poéticos) que nada tienen en común con las idealizadas protagonistas de los relatos intercalados.

El episodio de Guacolda y Lautaro (XIII, 43-XIV, 13) ofrece uno de los mejores pasajes líricos de La aralucand: el diálogo de los amantes la víspera del asalto al fuerte de Mataquito. Guacolda es una figura misteriosa que desaparece después de $1_{a}$ muerte de Lautaro. Ercilla no la caracteriza físicamente; sólo se refiere a ella como "la bella Gua. colda" e insiste en cambio en el amor fiel que la une a Lautaro. En la expresión poética es aquí evidente la huella de Garcilaso, tanto en la repetición de temas e imágenes tradicionales de la lírica petrarquista como en reminiscencias verbales. ${ }^{6}$ Al prometer fidelidad a su amado hasta después de la muerte Guacolda se expresa en términos convencio. nales de la poesía amorosa y Lautaro recrea el tema de la vida del enamorado en poder de su amado, clásico de la retórica petrarquista y garcilasiana. ${ }^{7}$

- La influencia de Garcilaso en la lengua de Ercilla ya ha sido señalada por J. T. Medina, cf. ob. cit. Ilustraciones, I y recientemente, de modo general, por Eugenio Florit, "Los momentos líricos de La araucana", RI, XXXIII (1967) 45.54 .

7 Cf. La araucana, XIII, 47, 7-8 y XIII, 49, 7-8 respectivamente y Garcilaso, Soneto V, por ejemplo. Para la representación del amor como fuego, lugar común petrarquista, of. XIII, 43 y entre muchos ejemplos en el Canzoniere de Petratca, Soneto LXV, Soneto CLXXV y en Garcilaso, Egloga Ir, v. 423, Soneto XVIII, etc. El amor como herida es de igual tradición: cf. La araucana, XIII, 49: "la llaga de amor está tan viva". etc. 
Los recuerdos verbales son también significativos; para citar un par de ejemplos solamente, cf. estrofa 46: "el áspero camino de mi suerte" y Garcilaso, Soneto VI: "Por ásperos caminos he llegado..." o Gar. cilaso, Canción IV, 20: "torna a seguir el áspero camino". La estrofa 56: "el preciso hado y dura suerte" repite con variantes los v. 76-77 de la Elegía I de Garcilaso: " $O$ Oh miserablos hados! ¡Oh mesquina suerte. . y dura..."

Ercilla mismo, por otra parte, nos da las pautas de los que podrían haber sido sus modelos en la poesía amorosa. Véase por ejemplo el comienzo del canto $\mathrm{XV}$, estrofa 2 :

\section{Dante, Ariosto, Petrarca y el Ibero amor los trujo a tanta delgadeza:}

¿Quién es el Ibero? J. T. Medina suponía que se trataba de Lucano. Pero es más sensato suponer que Ercilla pensó en Garcilaso. ${ }^{\circ}$ En efecto, Lucano no parece tener cabida entre los autores mencionados; históri. camente queda fuera de la secuencia que se complementa mejor con Garcilaso. Además, Ercilla no tomó de la Farsalia ningún episodio amo. roso y en cambio los paralelos con Garcilaso son evidentes.

En cuanto al contenido de este episodio, los críticos han señalado semejanzas con la despedida de Héctor y Andrómaca (cf. Ilíada, canto VI). ${ }^{10}$ Sin embargo, la relación con la Iliadd es muy remota. Si Ercilla tuvo presente algún texto al escribir este relato fue probablemente el Orlando furioso, canto XXX, 38.42.11 $\mathrm{La}$ estrofa 54 del canto XIII: "Harto claro / mi poca estimación por vos se muestra..." condensaría el sentido de las estrofas 38 a 42 del Orlando. Véase especialmente:

¿en tan flaca opinión está Lautaro, $\mathrm{y}$ en $\tan$ poco tenéis la fuerte diestra

y Orlando furioso, estrofa 38 :

8 J. T. Medina, ob. cit., Ilustraciones, I, p. 312.

- M. Chevalier, ob. cit. p. 151, n. 180, quien teitera la opinión de Menéndez y Pelayo, cf. Historia de la poesia bispanoamericana en Obras completas (Santander, 1948), t. 28 , p. 227.

10 'Véase, pot ejemplo, Royer, Etude littéraire sur l'Araucana d'Ercilla (Dijon, 1879) p. 166 y luego C. V. Aubrun, "Poesía épica y novela: el episodio de Glaura en La araucana", RI, XXI (1956) 261-273 (cf. p. 263).

11 Ducamin ya había señalado que Ercilla se inspiró en el diálogo de Doralice y Mandricardo, Orlando furioso, XXX, 38-42 que corresponde a La araucana, XIII, 54. Relación aceptada por Chevalier, ob. cit. p. 152. 
Ben mi mostrate in poco conto avere si per me un Ruggier sol vi $f_{a}$ temere.

La historia de Guacolda y. Lautaro se diferencia de las restantes por la falta de acción y aventura. La emoción está concentrada en el diálogo de los amantes y el tono trágico se ve acentuado por sueños premonitorios y por el choque entre la realidad y las esperanzas de Lautaro.

Se ha señalado que el episodio de Tegualda y Crepino (XX, 36. $\mathrm{XXI}, 12)$ se inspira parcialmente en la historia de los amores trágicos de Isabella y Zerbino, Orlando furioso, canto XIII y siguientes. ${ }^{12}$ Las coincidencias no son evidentes en cuanto a la anécdota; Ercilla, en cambio, parece haber tenido presente el texto para la expresión poética de algunos de sus pasajes. De todos modos, aunque se pueda rastrear el origen literario de algunos incidentes, Ercilla es original en la recreación y armonización de los temas. El recurso de presentarse a sí mismo como testigo da a la historia carácter de cosa vivida y real.

El episodio comienza con la presentación de la figura de Tegualda, viuda, que va al campamento enemigo a buscar el cadáver de su marido para enterrarlo. María Rosa Lida ya ha señalado el recuerdo de Argía, la mujer de Polynices (cf. Estacio, Thebaida, XII, 177 y ss.). ${ }^{13}$ Se puede mencionar también el paralelo con la historia de Abradatas, el rey de Susa que se une a las fuerzas de Ciro y muere en la lucha con los egipcios, y su mujer Panthea, en la Cinopedia de Jenofonte. ${ }^{14}$ Pan. thea, como Tegualda, llora sobre el cadáver de Abradatas y luego se suicida en prueba de fidelidad amorosa. Sirve de marco al relato la llegada de Tegualda al campamento español y el llanto sobre el cuerpo de Crepino. Al encontrar a Ercilla, narra Tegualda su historia en primera persona.

Varios elementos que recuerdan relatos caballerescos confluyen aquí. La competencia de los pretendientes por la mano de Tegualda fue com. parada con Orlando furioso, XIII, 6; pero lo que en Ariosto es una breve mención:

Trasse la fama ne le terre nostre cavallieri a giostrar di piu paesi.

\footnotetext{
13 Ducamin, L'araucana, poème épique, par Don Alonso de Ercilla y Zúñiga, Morceaux choisis ... (Paris, 1900) p. 149, n. 1. Véase también Chevalier, ob. cit. P. 152.

18 Cf. M. R. Lida, art. cit. p. 379.

is Ya señalado por Menéndez y Pelayo. Cf. Ciropedia, V, i, 3; VI, i, 45-49; VII, i, 29-32; VII, iii, 8-13 y VII, iii, 14.
} 
está desarrollado con gran detalle en La ardacana (cf. estrofas 40 y ss.), Ercilla describe minuciosamente, al uso caballeresco, el lugar donde se realizan las fiestas; un prado de estirpe garcilasiana:

el agua clara en torno murmuraba

los árboles movidos por el viento

hacían un movimiento y un ruido

que alegraban la vista y el oído.

En este escenario neoplatónico Crepino vence la indiferencia de Te, gualda. Como en otros relatos caballerescos se pone al servicio de la dama (estrofa 52) y le ofrece su lucha según las reglas de la cortesía. Lo más logrado desde el punto de vista poético es la descripción del apasionamiento en Tegualda. Isabella lo expresa muy brevemente: cf. Orlando furioso, XIII, 7:

Il qual poi che far pruove in campo vidi

miracolose di cavalleria,

fui presa del suo amore;

En Tegualda, a partir del violento enamoramiento a primera vista (cf. estrofa 54), hay una progresión constante del conflicto en el que luchan la pasión y el recato hasta que vence el amor por Crepino: cf. estrofa 58:

no sé si fue su estrella o fue mi hado...

que comencé a temblar y un fuego ardiendo

fue por todos mis huesos discurriendo.

Y luego sucesivamente, estrofas 59 y 60 :

Pero bajé los ojos al momento

de la honesta vergüenza reprimidos, y el mozo con un largo of recimiento inclinó a sus razones mis oídos.

Sentí una novedad que me apremiaba la libre fuerza y el rebelde brío, a la cual sometida se entregaba la razón, libertad y el albedrío. 
Yo, que cuando acordé, ya me hallaba ardiendo en vivo fuego el pecho frío, alcé los ojos tímidos cebados, que la vergüenza allí tenía abajados.

Cf. también estrofa 62, que marca la ruptura de la resistencia:

Roto con fuerza súbita y furiosa

de la vergüenza y continencia el freno, le seguí con la vista deseosa, cebando más la llaga y el veneno;

El relato caballeresco está mezclado con recuerdos verbales del libro IV de la Eneida. ${ }^{15}$ También deben citarse paralelas influencias de Ariosto. Chevalier menciona dos pasajes en los que el poema sigue al Orlando furioso. ${ }^{16}$ C. La araucana, XX, 75, 7-8:

haznos con esa espada y mano dura iguales, en la muerte y sepultura.

corresponderia a Ollando furioso, XXIV, 81, 7-8:

o se quel non puo tanto, io vi prometto con questa spada oggi passarmi il petto.

Y La araucana, XX, 76, 2:

un llanto tal que el monte enternecía

recuerda al Orlando furioso, XXIV, 86, 3.4:

e stride si, ch'intorno ne risuona

a molte miglia il bosco e la campagna.

15. Para citar sólo unos pocos ejemplos, of. La araucana, XX, 62, 4: "cebando más la llaga" y Eneida, IV, 2: "volnus alit venis"; La araucana, XX, 58 , 7-8: "un fuego ardiendo /fue por todos mis huesos discurriendo" y Eneida, IV, 101: "Ardet amans Dido traxitque per ossa furorem" y aun La araucana, XX, 61, 5-6: "Y2 me hallaba ardiendo en vivo fucgo" y Eneida, IV, 68: "uritur infelix Dido", etc.

16 Cf. ob. cit. p. 152. 
Podemos agregar todavía como probable fuente de La araucana, $\mathrm{XXI}, 8,4-7$ :

sobre ella se arrojó desatinada;

y junto con la suya de abundante

flujo de vivas lágrimas bañada.

Orlando furioso, XXIV, 86, 1-2:

Sopra il sanguigno corpo s'abbandona

e di copiose lacrime lo bagna.

$\mathrm{Y}$ con algunas variantes, La araucana, XXI, 10 recuerda al Orlando, XXIV, 86, 4-8.

En este episodio Ercilla combina y desarrolla temas caballerescos dentro de una estructura mayor que le sirve para presentar un caso trágico atractivo. Como narrador, Ercilla encarece la constancia y fidelidad de Tegualda, a la que parangona con las más famosas heroínas grecorromanas: Camila, Dido, Penélope, Lucrecia, Porcia y otras (cf. XXI, 3), como podía esperarse.

El episodio de Glaura y Cariolán (XXVIII, 3.44), a su vez, of rece nuevas posibilidades para presentar un relato novelesco de acción rápida y gran dinamismo que recuerda a la novela de aventuras de los siglos XVI y XVIr. También aquí Ercilla es actor en la historia y ayuda a solucionar el conflicto concediendo la libertad a Cariolán. Este recurso no implica que la historia de Glaura esté inspirada en un hecho real. Las aventuras de Glaura son tan "literarias" como las de Tegualda y la estructura del episodio debe ser estudizda en su propósito artístico, sin que haya necesidad de explicar presuntas fallas por la relación con una experiencia vital de Ercilla. ${ }^{17}$

La variedad de elementos que ofrece este telato hace complejo el establecimiento de una única fuente. Aubrun sugiere una serie de posibilidades de diversa procedencia. ${ }^{18} \mathrm{El}$ recurso de introducir a los personajes por medio de un encuentro casual sería típico de la técnica de Boccaccio, que Ercilla plido haber conocido a través de Timoneda. La escena del reconocimiento de Glaura y Catiolán recuerda la anagnórisis de las novelas bizantinas. Otros elementos novelescos son el disfraz y

17 Cf. Aubrun, art. cit., p. 264. La explicación de Aubrun parece hoy inaceptable.

18 Cf. Aubrun, p. 265 y ss. 
la aparición de los negros malhechores que intentan despojar a Glaura de su honor. Un último recuerdo literario sería la liberación de Cariolán por Ercilla, que pudo haber sido inspirada por la "Historia de Abindatráez y la Hermosa Jarifa". Todas estas relaciones son aceptables; pero el único recuerdo seguro y comprobable es el de Ariosto que ya citaba Ducamin. ${ }^{19}$

Ercilla se inspira nuevamente en el episodio de Isabella y Zerbino que ya había usado en la historia de Tegualda y Crepino. Glaura, como Isabella, relata su historia en primera persona: cf. La araucana, XXVIII, 7:

Mi nombre es Glaura en fuerte hora nacida

hija del buen cacique Quilacura.

y Orlando furioso, XIII, 4 :

Isabella sono io, che figlia fui

del re mal fortunato di Gallizia,

Ercilla libera a los amantes como hace Orlando con Isabella y Zerbino (cf. Orlando furioso, XIII y XXIII). Además de estos dos puntos coincidentes señalados por Aubrun hay otros recuerdos del mismo episodio que Ercilla mezcla libremente. Odorico intenta seducir a Isabella como Fresolano a Glaura. Isabella se salva por la llegada inesperada de una turba de malhechores (cf. Orlando furrioso, XIII, 29 y ss.) como Glaura se libra de Fresolano por la aparición de un escuadrón de españoles (cf. La araucana, XXVIII, 17). El reconocimiento final tam. bién recuerda el de Zerbino e Isabella (Orlando furioso, XXIII, 68.69) y no parece que haya necesidad de recurrir a la novela bizantina para explicar este recurso.

En resumen, Ercilla sigue a Ariosto en la creación de estos episodios amorosos, pero maneja su fuente con gran libertad. Basándose en un episodio del Owlando, elabora una historia original que anticipa futuros relatos novelescos. Sorprenden su habilidad para crear suspenso dramático y la agilidad y rapidez con que se suceden las desventuras de Glaura, preocupada siempre por su honor y castidad. La preocupación por el honor españoliza tan obviamente al personaje que traslada el episodio al campo de la ficción y hace altamente cuestionables analogías con la realidad araucana. Ercilla describe el valor y arrojo de su

10 Cf. Ducamin, ob. cit. p. 199, n. 1. 
heroina, que llega en busca de su marido, con el mismo detalle con que había descripto su belleza física (cf. estrofas 4 y 5 ). Liberando a ambos el autor parece premiar el valor de los indios.

Dos escenas más incluye Ercilla en La arducana que no llegan a ser verdaderos episodios. La primera es el encuentro con la joven Lauca (cf. XXXII, 32.43), arquetipo de mujer fiel, que busca la muerte para no vivir sin su marido. Este ejemplo de la fidelidad conyugal le permite introducir el relato de la verdadera historia de Dido (cf. XXXII, 43 y ss.). En la segunda aparece Fresia, la mujer de Caupolicán, cuando es tomado prisionero por los españoles (XXXIII, 73-83). Se podría suponer que la figura de Fresia, por lo que tiene de ruda y fuerte, se aproxima a la que Ercilla nos da de las mujeres araucanas;20 el poeta le aplica adjetivos con los que siempre caracteriza a los indios. Cf. estrofa 82:

Diciendo esto, colérica y rabiosa
el tierno niño le arrojó delante
y con ira frenética y furiosa,
se fue por otra parte en el instante.

Sin embargo, la escena cumple una función dramática y sirve para acentuar el fracaso de Caupolicán. Fresia se expresa con retórica elabo. rada reiterando las mismas promesas de fidelidad más allá de la muette que el poeta ha puesto en boca de otras heroínas del poema (cf. 80, 4-8). Fresia es, pues, también una figura heroica inventada por Etcilla.

En conclusión, el estudio de las heroínas indias del poema puede ser una pauta útil para deslindar poesía de historia en La araucana. Si aún es necesario insistir en que La araucana es primordialmente ficción antes que historia nada mejor que observar la recreación de temas y figuras de raigambre literaria en los episodios amorosos intercalados. En búsqueda de variedad y equilibrio en el poema, Ercilla rompe la monotonía del relato de sucesos bélicos incorporando, como pedía el modelo épico, escenas amorosas y personajes que responden a experiencias literarias $\mathrm{y}$ no vitales.

\section{Fordham University.}

Ĺ́A SCHWARTZ LERNER

20 Cf. Royer, ob. cit. p. 162; Royer considera que Fresia responde a una figura real. De la misma opinión es W. Strohmeyer, Studien jüer die Araukan des Don Alonso de Erfilla, (Bonn, 1929). 
